\title{
Assessment of the Thermal Effectiveness of Mineral Warmers for Protective Gloves Used in Cold Environments
}

\author{
Emilia Irzmańska $^{1 *}$, Magdalena Jurczyk-Kowalska² \\ ${ }^{1}$ Central Institute for Labour Protection - National Research Institute, Department of Personal Protective Equipment, \\ Wierzbowa 48, Lodz 90-133, Poland \\ ${ }^{2}$ Warsaw University of Technology, Faculty of Materials Science and Engineering, Woloska 141, Warsaw 02-507, Poland
}

Corresponding Author Email: emirz@ciop.lodz.pl

https://doi.org/10.18280/ijht.380104

Received: 24 October 2019

Accepted: 16 December 2019

\section{Keywords:}

protective gloves, cold working environment, mineral warmers, thermal effectiveness

\begin{abstract}
The objective of the study was to assess the thermal effectiveness of mineral warmers for protective gloves used in cold environments. The study material consisted of protective gloves integrated with mineral warmers, constituting chemical heating garments (CHGs). The mineral warmers differed in terms of the amount of active mineral compounds and geometry. The warmers were applied in three protective glove that met the thermal insulation requirements stipulated in the standard EN 511:2006. The thermal effects associated with glove design and mineral warmer geometry were evaluated by recording temperature changes inside gloves placed in a climatic chamber. Continuous tests were conducted for $6 \mathrm{~h}$ under dynamic conditions simulating the work cycle with measurement intervals of varying length under selected ambient temperatures $\left(-15^{\circ} \mathrm{C},-10^{\circ} \mathrm{C}, 0^{\circ} \mathrm{C}, 5^{\circ} \mathrm{C}\right.$, $10^{\circ} \mathrm{C}$ ) and a relative humidity of $60 \pm 5 \%$. The results were statistically evaluated using analysis of variance (ANOVA) in order to identify differences in thermal effect between the gloves depending on the type of mineral warmers, glove design, and ambient temperature of the work environment. It was found that the use of mineral warmers significantly increased the temperature inside all the studied models of protective gloves. The smallest amount of thermoactive mixture $(10 \mathrm{~g})$ was insufficient to maintain thermal comfort over the adopted work period of $6 \mathrm{~h}$. The optimum amount of mineral compounds ensuring a good thermal effect for periods shorter than the adopted $6 \mathrm{~h}$ work cycle was 20 $\mathrm{g}$ for the proposed warmer package design.
\end{abstract}

\section{INTRODUCTION}

A variety of efforts have been undertaken according to the current state of the art to alleviate the adverse effects of cold environments on worker comfort [1]. Over time, personal protective products have become increasingly multifunctional and tend to exhibit thermal properties appropriate for workplace hazards [2, 3]. New solutions are being developed to incorporate smart systems for monitoring cold work environments or active materials (heated with electric cells, phase change compounds, or active mineral compounds using simple chemical reactions with atmospheric oxygen) [4].

Work in cold environments causes hand cooling and impairs the manual ability of workers [5-7]. In practice, coldprotective gloves should primarily provide good thermal insulation [8], be ergonomic [7], and actively maintain appropriate hand skin temperature [9].

It should be noted that while gloves with good thermal properties protect the user against the adverse effect of cold work environments, they may also significantly hinder heat preservation [10]. That fact is associated with the type and number of layers as well as the surface density of the materials used in the various structural elements of the glove [11]. In addition, the amount of perspiration exuded by the hand skin may increase or decrease depending on the ambient temperature, work strain (light or strenuous manual labor), and individual differences $[12,13]$. According to the literature, the optimum conditions inside protective gloves are $\mathrm{RH} \leq 50 \%$ and $\mathrm{T} \leq 33^{\circ} \mathrm{C}$ for light manual work and $\mathrm{RH} \leq 80 \%$ and $\mathrm{T} \leq$ $33^{\circ} \mathrm{C}$ for intensive manual work. An important variable affecting the thermal properties of gloves and thermal hand comfort is the moisture accumulating under the protective barrier. In combination with manual factors of various intensity, moisture may reduce glove insulation properties by up to $45 \%[14,15]$.

Hand protection products may employ a variety of methods to reduce heat loss [16]. The most traditional products of this type are gloves made of textile materials with different thermal properties. Alternative solutions include active or passive heat sources incorporated in personal heating garments (PHGs) designed for various body parts exposed to cold work environments. PHGs can be divided into several groups, based on the nature of the heating process [17]. New ideas have also been developed for combining the protective properties of gloves with thermal effects. New designs of electrically heated clothing (EHC) include heating elements, thermal control systems, and a power supply with a user interface for controlling the equipment [18]. They can operate for up to several hours, and their operation time is only limited by the durability of power supply or battery lifetime. However, their performance is limited as they do not offer satisfactory protection from extreme cold environments, and their impact 
on human health has not been sufficiently elucidated [19]. Indeed, those solutions do not always meet the users' expectations. Gloves incorporating such systems are rigid and heavy, and so in many workplaces those disadvantages may outweigh the benefits derived from additional heat. Efforts to optimize heated hand protective products have been under way for many years now. Due to the complexity of the issue, many workers remain at risk of excessive cooling of the upper extremities [20].

While cutting-edge technologies are being deployed in the design process, to date no practical solution has been developed that could be universally applied. Among the promising technologies are passive heat sources containing mineral compounds or gels placed in pouches and structurally integrated with the product. Another group of warmers are used in chemically heated garments (CHGs) [21]. They generate heat by means of substances entering into exothermic reactions, such as oxidation. That category of warmers is characterized by a more advanced composition and their heating performance lasts longer than that of sodium acetatebased warmers. The oxidizing agent typically used in CHGs is powdered iron. When exposed to air, iron oxide $\mathrm{Fe}_{2} \mathrm{O}_{3}$ is formed in the process of accelerated "rusting" according to the formula: $4 \mathrm{Fe}+3 \mathrm{O}_{2} \rightarrow 2 \mathrm{Fe}_{2} \mathrm{O}_{3}$. However, the reaction might not take place fast enough without catalysts. To initiate and maintain the reaction, other compounds need to be included in CHGs, as specified in Table 1.

Table 1. Compounds used in mineral warmers for chemically heated protective clothes [21]

\begin{tabular}{cc}
\hline Compound & Action \\
\hline Iron & $\begin{array}{c}\text { An oxidizing agent forming iron } \\
\text { oxide. }\end{array}$ \\
\hline Chloride ions/salts & $\begin{array}{c}\text { Catalysts for further acceleration of } \\
\text { the oxidation reaction. }\end{array}$ \\
\hline Activated carbon & $\begin{array}{c}\text { Oxidation reaction catalyst; it helps to } \\
\text { evenly distribute the generated heat } \\
\text { across the warmer to prolong its } \\
\text { thermal effects; it also absorbs and } \\
\text { retains the odors, water, and water } \\
\text { vapor generated in the process. }\end{array}$ \\
\hline Cellulose & $\begin{array}{c}\text { Keeps the generated moisture inside } \\
\text { the warmer. }\end{array}$ \\
\hline Water & Accelerates the oxidation process. \\
\hline $\begin{array}{c}\text { Minerals e.g. } \\
\text { vermiculite, diatomite; } \\
\text { pulverized wool; } \\
\text { polyacrylate }\end{array}$ & $\begin{array}{c}\text { Absorbent material that helps to retain } \\
\text { the generated moisture inside the } \\
\text { warmer to enable the oxidation } \\
\text { reaction; it also acts as an insulator, } \\
\text { keeping heat inside the warmer. }\end{array}$ \\
\hline
\end{tabular}

Mineral warmers may be applied in functional and hygienic products adjustable to individual requirements by changing the amount of heat generated, depending on different temperatures of exposure to cold [22].

The objective of the study was to assess the effects of the geometry of mineral warmers and protective glove design on heat retention in simulated cold work environments.

\section{MATERIALS}

The study material consisted of protective gloves integrated with heating elements such as mineral warmers. A general idea of the operation of warmers is given in Figure 1.

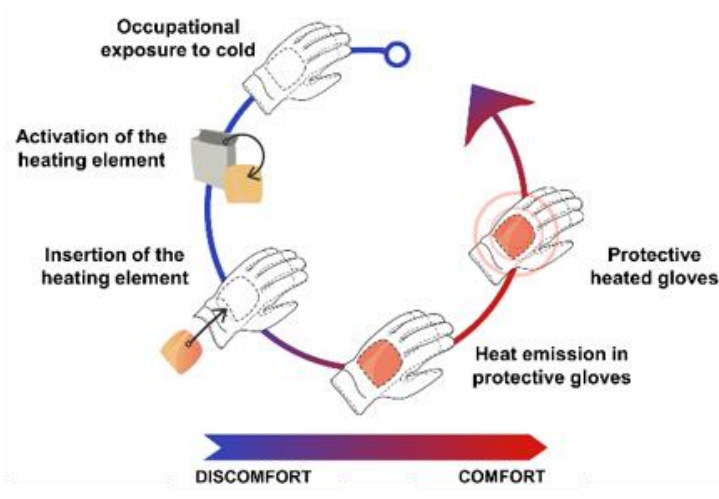

Figure 1. Idea of the operation of mineral warmers applied in protective gloves

\subsection{Mineral warmers}

The study involved three types of mineral warmers differing in terms of the amount of active mineral compounds (10 g, 20 $\mathrm{g}$, and $26 \mathrm{~g}$ ) and in two geometric forms. The warmers contained commercially available mineral powder compositions (JAKAR, Poland) consisting of iron (Fe), vermiculite, diatomite, salt, and activated carbon, as well as water. Depending on the design of the heating element, the amount of thermoactive powder, and iron content, the time of activity lasted from 6 to $14 \mathrm{~h}$. The heating elements had been developed as part of a research project, with the physical and chemical aspects described in detail in another paper by the Authors [15]. The heating element consisted of an outer casing and an inner casing containing the exothermal mixture. The inner casing consisted of a perforated two-layer material. The geometry of the mineral warmers is shown in Table 2.

Mineral warmers were designated as MW1, MW2, and MW3. The variants MW1 and MW2 were identical in size and shape, but differed in terms of the weight of mineral powder and iron content. The size and shape of MW3 were different from the other two variants. The above mineral warmers were compared to reference gloves (glove variant G0 without mineral warmers, designated as MW0).

The shapes of the mineral warmers presented in this paper had been already optimized in ergonomic studies on human subjects, as described in another paper by the Authors [23].

\subsection{Protective gloves}

Figure 2 characterizes the three variants of protective gloves that are most frequently used by workers occupationally exposed to cold [REK-SWED, Poland]. These gloves were selected, both in terms of material and design, based on a survey administered to 107 users of protective gloves workers of cold storage facilities (the survey results were described at length in another paper by the Authors) [11]. The selected gloves were found to comply with the thermal insulation requirements for cold workplace environments as determined using a thermal hand model according to the standard EN 511:2006 [24], as reported in another paper by the Authors [10].

All variants incorporated an inner knitted polyester pouch integrated with the glove to accommodate the heating element. The design of the pouch and its positioning within the glove are protected as a utility model, with detailed construction information given in the Authors' patent application [25]. 
The studied glove variants (G1, G2, and G3) incorporating mineral warmers (MW1, MW2, or MW3) were compared with reference gloves (G0). The reference gloves were the studied gloves without the warmers.

Table 2. Characterization of the mineral warmers used in the study

\begin{tabular}{|c|c|c|c|c|}
\hline Wariant & Mineral warmer (MW) variant and geometry & Weight & Duration of activity claimed by manufacturer & $\begin{array}{c}\text { Iron }(\mathrm{Fe}) \text { content } \\
{[\%]}\end{array}$ \\
\hline MW1 & & $10 \pm 1 \mathrm{~g}$ & $6 \mathrm{~h}$ & $13.6 \pm 1.2$ \\
\hline MW2 & 38 & $20 \pm 1 \mathrm{~g}$ & $8 \mathrm{~h}$ & $15.2 \pm 2.1$ \\
\hline MW3 & จ & $26 \pm 1 \mathrm{~g}$ & $14 \mathrm{~h}$ & $21.5 \pm 1.2$ \\
\hline & & & & \\
\hline
\end{tabular}

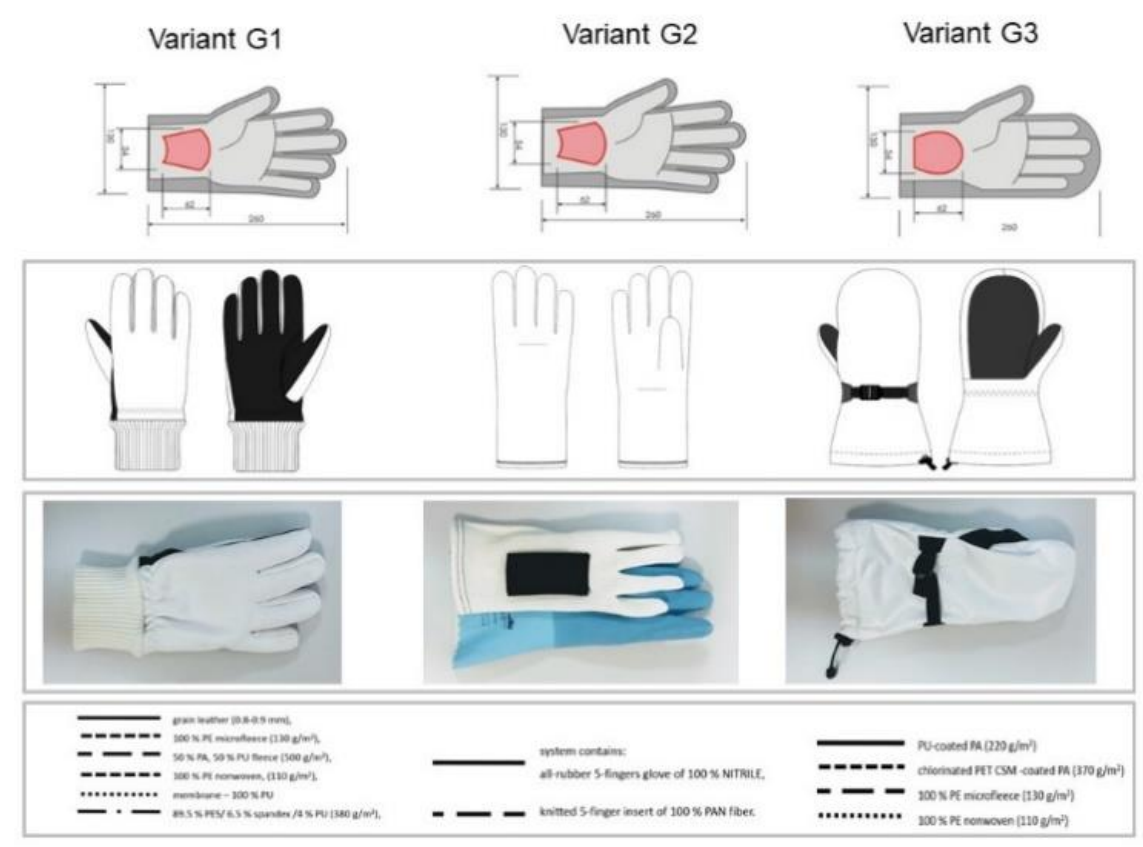

Figure 2. Design and materials used in the studied gloves

\section{METHODOLOGY OF COLD WORK ENVIRONMENT SIMULATION}

Figure 3 shows the research procedure used in the study - a series of dynamic tests reflecting a work cycle typical of cold environments, including measurement intervals of different lengths. The procedure is based on data concerning workplace temperature and humidity as well as worktime patterns obtained from a survey of 107 cold storage workers. It reflects the fact that for the first $2 \mathrm{~h}$ of an $8 \mathrm{~h}$ shift no additional glove heating is needed, as reported in another work by the Authors [11]. Furthermore, the procedure accounts for the fact that in cold storage facilities workers periodically move to warm rooms during breaks.
Protective glove tests were conducted using a climatic chamber (SANYO, Japan) to simulate workplace temperatures of $10^{\circ} \mathrm{C}, 5^{\circ} \mathrm{C}, 0^{\circ} \mathrm{C},-10^{\circ} \mathrm{C}$, and $-15^{\circ} \mathrm{C}$ at a relative humidity of $60 \%$.

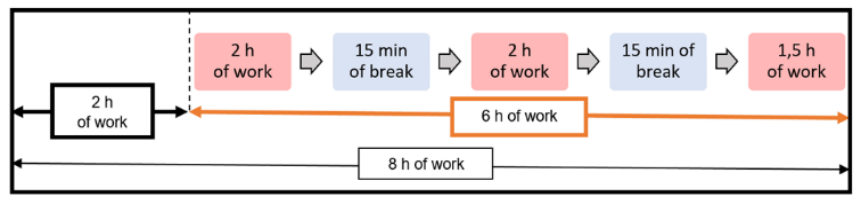

Figure 3. Series of dynamic tests simulating an $8 \mathrm{~h}$ work cycle 
The temperature inside protective gloves with mineral warmers was measured using iButton sensors (USA). The sensors were placed on the mineral warmers in the pouches located in the dorsal part of gloves, as shown in Figure 4.

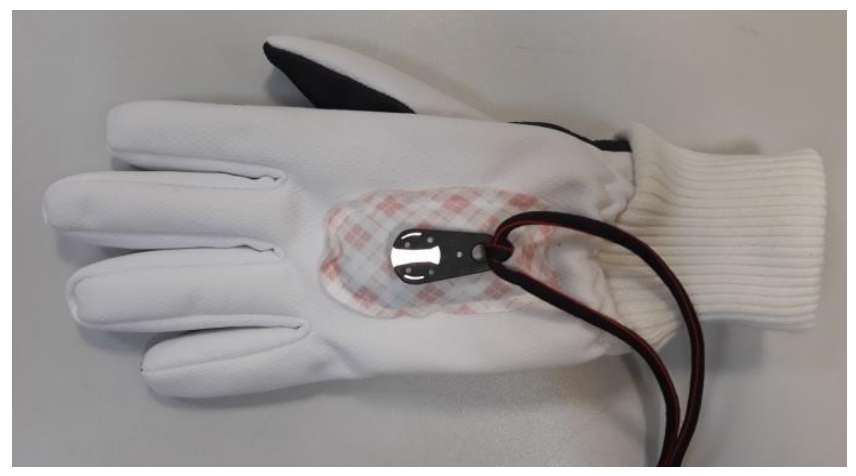

Figure 4. Location of mineral warmer and a T/RH sensor inside an inner pouch

The studied mineral warmers implemented in gloves were placed in a climatic chamber with the ambient temperature and humidity set to parameters representative of cold work environments. Temperature measurements were conducted simultaneously for four protective gloves (three measurements for G1, G2, and G3 variants and one measurement for the reference variant G0). The reference measurement was used for evaluating the temperature differences obtained inside protective gloves integrated with mineral warmers.

The procedure for climatic chamber tests was as follows:

-removal of mineral warmers from their cases;

- shaking the mineral warmers to break up the mineral powder and activate an exothermal reaction in the presence of oxygen;

-placing the mineral warmers and $\mathrm{T} / \mathrm{RH}$ sensors in pouches inside protective gloves,

-placing the gloves in the climatic chamber;

- continuous recording of changes in the temperature of mineral warmers over $6 \mathrm{~h}$ every $60 \mathrm{~s}$ under conditions simulating a work cycle ( $2 \mathrm{~h}$ of work, $15 \mathrm{~min}$ of break, $2 \mathrm{~h}$ of work, 15 min of break and $1.5 \mathrm{~h}$ of work) at the specified ambient temperatures and a relative humidity of $60 \pm 5 \%$,

-measurement termination and reading of recorded data.

\subsection{Statistical analysis}

The collected data were analyzed statistically using SPSS Statistics 25.0 in order to identify temperature differences inside protective gloves over an $8 \mathrm{~h}$ work cycle depending on the mineral warmer type, protective glove variant, and simulated ambient temperature of the workplace $\left(-15^{\circ} \mathrm{C}\right.$, $10^{\circ} \mathrm{C}, 0^{\circ} \mathrm{C}, 5^{\circ} \mathrm{C}, 10^{\circ} \mathrm{C}$ ). Analysis of variance (ANOVA) was used with a posteriori bootstrapping with 1000 replicates. Post-hoc comparisons were made using the Bonferroni test. The statistical significance level was adopted at $\mathrm{p}<0.05$.

\section{RESULTS}

Descriptive statistics for temperature measurements inside protective gloves over an $8 \mathrm{~h}$ work cycle depending on the type of mineral warmers, protective glove variant, and ambient temperature are given in Table 3 .

Figure 5 presents changes in temperature over $6 \mathrm{~h}$ of activity of mineral warmers with different geometries inside protective gloves.

Table 3. Descriptive statistics for temperature measurements inside protective gloves over an $8 \mathrm{~h}$ work cycle depending on the type of mineral warmers, protective glove variant, and ambient temperature

\begin{tabular}{|c|c|c|c|c|c|c|c|c|c|c|c|c|c|c|}
\hline \multirow{4}{*}{\multicolumn{2}{|c|}{ 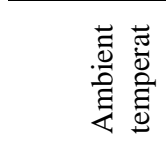 }} & & \multicolumn{12}{|c|}{ Mineral warmers } \\
\hline & & & \multicolumn{3}{|c|}{ MW0 } & \multicolumn{3}{|c|}{ MW1 } & \multicolumn{3}{|c|}{ MW2 } & \multicolumn{3}{|c|}{ MW3 } \\
\hline & & & \multicolumn{12}{|c|}{ Gloves } \\
\hline & & & G1 & G2 & G3 & G1 & $\mathrm{G} 2$ & G3 & G1 & $\mathrm{G} 2$ & G3 & G1 & $\mathrm{G} 2$ & G3 \\
\hline \multirow{25}{*}{ 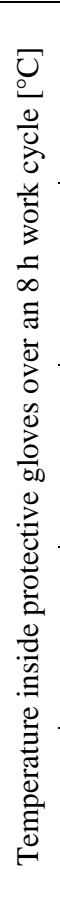 } & $-15^{\circ} \mathrm{C}$ & $\mathrm{N}$ & 6 & 6 & 6 & 6 & 6 & 6 & 6 & 6 & 6 & 6 & 6 & 6 \\
\hline & & Min & 0.00 & 0.00 & 0.00 & 0.00 & 0.00 & 0.00 & 0.00 & 0.00 & 0.00 & 0.00 & 0.00 & \\
\hline & & $\operatorname{Max}$ & 1.00 & 1.00 & 1.00 & 30.00 & 29.00 & 50.00 & 60.00 & 49.00 & 55.00 & 62.00 & 39.00 & 54.00 \\
\hline & & M & 0.33 & 0.33 & 0.33 & 7.83 & 8.50 & 16.50 & 29.33 & 16.33 & 25.50 & 34.50 & 18.17 & 39.17 \\
\hline & & SD & 0.52 & 0.52 & 0.52 & 11.63 & 11.41 & 19.03 & 29.84 & 18.25 & 23.76 & 24.91 & 16.99 & 13.53 \\
\hline & $-10^{\circ} \mathrm{C}$ & $\mathrm{N}$ & 6 & 6 & 6 & 6 & 6 & 6 & 6 & 6 & 6 & 6 & 6 & 6 \\
\hline & & Min & 0.00 & 0.00 & 0.00 & 10.00 & 0.00 & 0.00 & 20.00 & 0.00 & & & 0.00 & \\
\hline & & $\operatorname{Max}$ & 1.00 & 1.00 & 1.00 & 60.00 & 20.00 & 28.00 & 68.00 & 57.00 & 54.00 & 00 & 51. & 51.00 \\
\hline & & M & 0.33 & 0.33 & 0.33 & & 6.67 & & 42. & 25.03 & & & 25 . & 35.00 \\
\hline & & SD & 0.52 & 0.52 & 0.52 & 18.98 & 8.16 & 11.97 & 24.19 & 24.72 & 21.34 & 14.65 & 21.81 & 16.14 \\
\hline & $0^{\circ} \mathrm{C}$ & $\mathrm{N}$ & 6 & 6 & 6 & 6 & 6 & 6 & 6 & 6 & 6 & 6 & 6 & 6 \\
\hline & & $\mathrm{Mir}$ & 0.00 & 0.00 & 0.00 & 4.00 & 1.00 & 3.0 & 4.0 & 7.00 & 3.0 & 5.00 & 8.00 & 7.00 \\
\hline & & $\mathrm{Ma}$ & 7.00 & 7.00 & 7.00 & 61.00 & 18.00 & 53.00 & 51.00 & 51.00 & 57.00 & 63.00 & 47.00 & 54.00 \\
\hline & & M & 2.33 & 2.33 & 2.33 & 20.83 & 6.83 & 19.00 & 27.67 & 21.33 & 29.83 & 36.67 & 30.67 & 36.33 \\
\hline & & SD & 3.61 & 3.61 & 3.61 & 20.99 & 7.05 & 19.31 & 21.13 & 16.21 & 24.09 & 26.75 & 17.26 & 16.88 \\
\hline & $5^{\circ} \mathrm{C}$ & $\mathrm{N}$ & 6 & 6 & 6 & 6 & 6 & 6 & 6 & 6 & 6 & 6 & 6 & 6 \\
\hline & & Min & 5.00 & 5.00 & 5.00 & 10.00 & 7.00 & 10.00 & 10.00 & 7.00 & 9.00 & 24.00 & 28.00 & 9.00 \\
\hline & & Max & 11.00 & 11.00 & 11.00 & 60.00 & 35.00 & 54.00 & 69.00 & 58.00 & 60.00 & 68.00 & 54.00 & 65.00 \\
\hline & & M & 7.00 & 7.00 & 7.00 & 28.00 & 20.00 & 32.17 & 41.00 & 36.00 & 38.17 & 49.17 & 41.50 & 36.17 \\
\hline & & SD & 2.76 & 2.76 & 2.76 & 19.03 & 10.94 & 19.40 & 26.35 & 19.47 & 20.35 & 16.85 & 10.69 & 23.41 \\
\hline & $10^{\circ} \mathrm{C}$ & $\mathrm{N}$ & 6 & 6 & 6 & 6 & 6 & 6 & 6 & 6 & 6 & 6 & 6 & 6 \\
\hline & & Min & 10.00 & 10.00 & 10.00 & 14.00 & 16.00 & 15.00 & 15.00 & 16.00 & 25.00 & 15.00 & 4.00 & 22.00 \\
\hline & & Max & & & 13.00 & 46.00 & 50.00 & 53.00 & 71. & 62.00 & 53.00 & 70.00 & 35.00 & 53.00 \\
\hline & & M & 10.67 & 10.67 & 10.67 & 25.17 & 32.00 & 34.67 & 43.67 & 40.50 & 41.33 & 45.83 & 25.33 & 41.17 \\
\hline & & $\mathrm{SD}$ & 1.21 & 1.21 & 1.21 & 11.79 & 13.55 & 18.80 & 27.51 & 20.32 & 10.25 & 25.09 & 12.31 & 11.62 \\
\hline
\end{tabular}



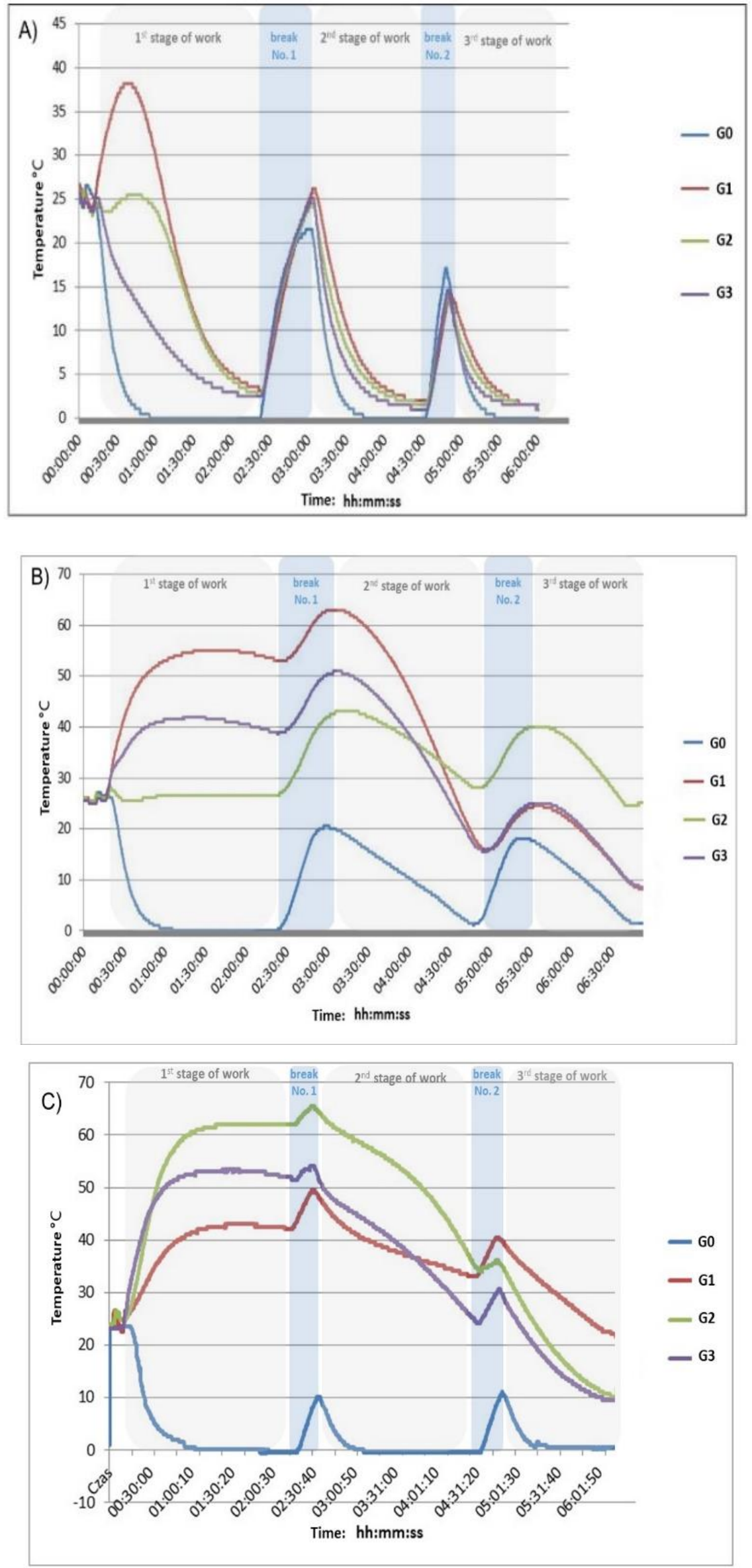

Figure 5. Changes in temperature over $6 \mathrm{~h}$ of activity of mineral warmers inside protective gloves: G0 (reference gloves), G1 (five-fingered gloves), G2 (five-fingered all rubber gloves with knitted inserts), and G3 (mitts), with the weight of warmers being A) $10 \mathrm{~g}$ (MW1); B) $20 \mathrm{~g}$ (MW2); and C) $26 \mathrm{~g}$ (MW3) 
Table 4 summarizes ANOVA statistics for the effects of mineral warmers on the temperature inside protective gloves over an $8 \mathrm{~h}$ work cycle depending on the glove variant and ambient temperature.
Figure 6 shows the effects of different mineral warmers on the temperature inside protective gloves over an $8 \mathrm{~h}$ work cycle depending on glove variant and ambient temperature.

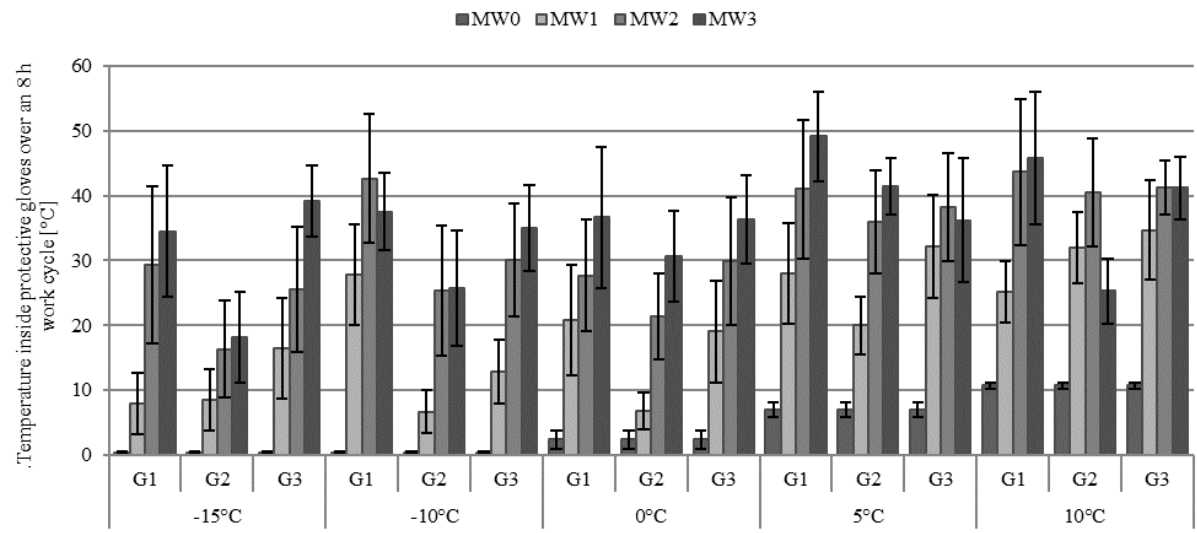

Figure 6. Effects of different mineral warmers on the temperature inside protective gloves over an $8 \mathrm{~h}$ work cycle depending on glove variant and ambient temperature

Table 4. ANOVA statistics for the effects of mineral warmers on the temperature inside protective gloves over an $8 \mathrm{~h}$ work cycle depending on the glove variant and ambient temperature

\begin{tabular}{|c|c|c|c|c|c|c|c|c|c|c|c|}
\hline \multirow{2}{*}{\multicolumn{2}{|c|}{ Ambient temperature }} & \multirow{2}{*}{ Glove variant } & & \multicolumn{4}{|c|}{ Mineral warmers } & \multirow{2}{*}{$\begin{array}{c}\text { Test } \\
\text { post-hoc }\end{array}$} & \multirow[b]{2}{*}{$F(3.20)$} & \multirow[b]{2}{*}{$p$} & \multirow[b]{2}{*}{$\eta^{2}$} \\
\hline & & & & MW0 & MW1 & MW2 & MW3 & & & & \\
\hline \multirow{30}{*}{$\begin{array}{l}0 \\
\stackrel{0}{0} \\
\stackrel{0}{0}\end{array}$} & \multirow[t]{6}{*}{$-15^{\circ} \mathrm{C}$} & G1 & $M$ & 0.33 & 7.83 & 29.33 & 34.50 & $0<1.2 .3 ; 1<3$ & 3.97 & 0.01 & 0.37 \\
\hline & & & & 0.52 & 11.63 & 29.84 & 24.91 & & & & \\
\hline & & $\mathrm{G} 2$ & $M$ & 0.33 & 8.50 & 16.33 & 18.17 & $0<1.2 .3 ; 1<3$ & 2.12 & 0.03 & 0.34 \\
\hline & & & SD & 0.52 & 11.41 & 18.25 & 16.99 & & & & \\
\hline & & G3 & M & 0.33 & 16.50 & 25.50 & 39.17 & $0<1.2 .3 ; 1<3$ & 5.74 & 0.01 & 0.46 \\
\hline & & & SD & 0.52 & 19.03 & 23.76 & 13.53 & & & & \\
\hline & \multirow[t]{6}{*}{$-10^{\circ} \mathrm{C}$} & G1 & $\mathrm{M}$ & 0.33 & 27.83 & 42.67 & 37.50 & $0<1.2 .3$ & 7.36 & 0.001 & 0.52 \\
\hline & & & SD & 0.52 & 18.98 & 24.19 & 14.65 & & & & \\
\hline & & G2 & $\mathrm{M}$ & 0.33 & 6.67 & 25.03 & 25.67 & $0<1.2 .3 ; 1<3$ & 3.50 & 0.03 & 0.34 \\
\hline & & & SD & 0.52 & 8.16 & 24.72 & 21.81 & & & & \\
\hline & & G3 & $\mathrm{M}$ & 0.33 & 12.83 & 30.17 & 35.00 & $0<1.2 .3 ; 1<3$ & 7.13 & 0.001 & 0.52 \\
\hline & & & SD & 0.52 & 11.97 & 21.34 & 16.14 & & & & \\
\hline & \multirow[t]{6}{*}{$0^{\circ} \mathrm{C}$} & G1 & $\mathrm{M}$ & 2.33 & 20.83 & 27.67 & 36.67 & $0<1.2 .3$ & 3.15 & 0.05 & 0.32 \\
\hline & & & SD & 3.61 & 20.99 & 21.13 & 26.75 & & & & \\
\hline & & G2 & $\mathrm{M}$ & 2.33 & 6.83 & 21.33 & 30.67 & $0<2.3 ; 1<3$ & 6.58 & 0.001 & 0.50 \\
\hline & & & SD & 3.61 & 7.05 & 16.21 & 17.26 & & & & \\
\hline & & G3 & $\mathrm{M}$ & 2.33 & 19.00 & 29.83 & 36.33 & $0<1.2 .3$ & 4.24 & 0.02 & 0.39 \\
\hline & & & SD & 3.61 & 19.31 & 24.09 & 16.88 & & & & \\
\hline & \multirow[t]{6}{*}{$5^{\circ} \mathrm{C}$} & G1 & $\mathrm{M}$ & 7.00 & 28.00 & 41.00 & 49.17 & $0<1.2 .3 ; 1<3$ & 6.02 & 0.001 & 0.47 \\
\hline & & & SD & 2.76 & 19.03 & 26.35 & 16.85 & & & & \\
\hline & & $\mathrm{G} 2$ & $\mathrm{M}$ & 7.00 & 20.00 & 36.00 & 41.50 & $0<1.2 .3 ; 1<3$ & 9.50 & 0.001 & 0.59 \\
\hline & & & SD & 2.76 & 10.94 & 19.47 & 10.69 & & & & \\
\hline & & G3 & $\mathrm{M}$ & 7.00 & 32.17 & 38.17 & 36.17 & $0<1.2 .3$ & 3.73 & 0.03 & 0.36 \\
\hline & & & SD & 2.76 & 19.40 & 20.35 & 23.41 & & & & \\
\hline & \multirow[t]{6}{*}{$10^{\circ} \mathrm{C}$} & G1 & $\mathrm{M}$ & 10.67 & 25.17 & 43.67 & 45.83 & $0<1.2 .3$ & 4.34 & 0.02 & 0.39 \\
\hline & & & SD & 1.21 & 11.79 & 27.51 & 25.09 & & & & \\
\hline & & $\mathrm{G} 2$ & $\mathrm{M}$ & 10.67 & 32.00 & 40.50 & 25.33 & $0<1.2 .3$ & 5.09 & 0.01 & 0.43 \\
\hline & & & SD & 1.21 & 13.55 & 20.32 & 12.31 & & & & \\
\hline & & G3 & $\mathrm{M}$ & 10.67 & 34.67 & 41.33 & 41.17 & $0<1.2 .3$ & 8.52 & 0.001 & 0.56 \\
\hline & & & SD & 1.21 & 18.80 & 10.25 & 11.62 & & & & \\
\hline
\end{tabular}

\section{DISCUSSION}

The experiments showed that thermal effects are substantially influenced by the application of chemical heating systems (mineral warmers) inside protective gloves. This fact translates into higher thermal comfort of workers using the gloves. Similar observations were reported by Song et al. and
Iserson $[14,26]$.

In the present study, the type of mineral warmers had a statistically significant effect on temperature inside protective gloves over an $8 \mathrm{~h}$ work cycle for all the three studied glove types and five simulated workplace temperatures. Irrespective of the ambient temperature and protective glove variant, the temperature for MW0 was lower than that for MW1, MW2, or 
MW3 (Figure 6). An exception was the G2 glove, where at an ambient temperature of $0^{\circ} \mathrm{C}$ differences were found only between MW0 and MW2 and MW3. In addition, MW1 provided significantly lower temperatures as compared to MW3 at an ambient temperature of $-15^{\circ} \mathrm{C}$ for gloves $\mathrm{G} 1, \mathrm{G} 2$, and $\mathrm{G} 3$, at $-10^{\circ} \mathrm{C}$ for $\mathrm{G} 2$ and $\mathrm{G} 3$, at $0^{\circ} \mathrm{C}$ for $\mathrm{G} 2$, and at $5^{\circ} \mathrm{C}$ for $\mathrm{G} 1$ and $\mathrm{G} 2$, and at $10^{\circ} \mathrm{C}$ for $\mathrm{G} 1$.

It was clearly shown that $10 \mathrm{~g}$ of thermoactive powder in the proposed packaging was insufficient to maintain the user's thermal comfort over the adopted period of $6 \mathrm{~h}$. The maximum amount of mineral compounds that could be placed in the mineral warmer package was $26 \mathrm{~g}$. It should be noted, however, that excessive packing of the powder may limit access to air and disturb the process of iron oxidation, hindering heat release. The optimum amount of mineral compounds in the proposed warmer packages was $20 \mathrm{~g}$.

Detailed results concerning temperature changes over the 6 $\mathrm{h}$ thermal activity of mineral warmers is given in Figure 5. Analysis shows that the mean temperature inside protective gloves increased with ambient temperature. The mean increase was $20.3^{\circ} \mathrm{C}, 24.1^{\circ} \mathrm{C}$, and $24.6^{\circ} \mathrm{C}$ for $\mathrm{G} 1, \mathrm{G} 2$, and $\mathrm{G} 3$ variants, respectively. The highest mean temperatures, usually occurring during the 2nd work interval, were found inside the G1 glove variant, while the lowest ones - inside G2. For gloves G1 and G3, the increment in mean inner temperature was the greatest during the $1 \mathrm{st}$ break (on average by $3.5^{\circ} \mathrm{C}$ and $0.9^{\circ} \mathrm{C}$ ), and for the $\mathrm{G} 2$ variant it was the highest during the 2 nd break (on average by $3.5^{\circ} \mathrm{C}$ ). It was noted that the higher the ambient temperature the greater the temperature increment inside the glove. The results show that the difference in peak temperature between gloves with and without mineral warmers did not exhibit a linear relationship with ambient temperature. For all of the studied protective gloves, it was higher during the first break in work. Mineral warmers caused the greatest temperature increase in G1 gloves (on average by $30.1^{\circ} \mathrm{C}$, or $32.1^{\circ} \mathrm{C}$ with respect to ambient temperature). The increase was the highest for the lowest ambient temperature (on average by $41.3^{\circ} \mathrm{C}$ ). For the highest ambient temperature, the mean increase amounted to $23.1^{\circ} \mathrm{C}$. The smallest temperature increment was noted for $\mathrm{G} 2$ gloves (on average by $17.8^{\circ} \mathrm{C}$, or $19.8^{\circ} \mathrm{C}$ with reference to ambient temperature). Also, for those gloves the increment was relatively the largest for the lowest ambient temperature (on average by $30.0^{\circ} \mathrm{C}$ as compared to $10.8^{\circ} \mathrm{C}$ for the highest ambient temperature).

Figure 5 shown activity of mineral warmers with different amount of active mineral compound. We can observe that the peak temperature on the third stage of activity of mineral warmers became to almost the same, this trend has not been confirmed. This is especially visible for gloves G1 (fivefingered gloves) and G3 (mitts) made of materials with similar insulation. For heaters containing $10 \mathrm{~g}$ of mineral powders (Fig. A) the thermal efficiency over time is significantly reduced. These heaters lose their heating capacity after 4 hours and for all types of gloves the temperature after the second break increases to the ambient temperature in the laboratory for all tested gloves. The heating process (thermal efficiency) for heaters containing $10 \mathrm{~g}$ of mineral powder is shorter than 6 hours. For heaters containing $20 \mathrm{~g}$ of mineral powders (Figure B), the heat release process is recorded for 6 hours. The thermal efficiency inside the tested gloves may be affected by the insulating properties of the gloves and not only the heat efficiency of the heaters.

An increase in the thermal effect inside gloves was corroborated by Iserson, Sands et al. as well as Wang et al. [14,
22, 27]. It should be stressed that those researchers examined heating systems in protective gloves (CHGs or EHCs) only in terms of temperature, without specifying the duration of the effect or the insulation offered over an $8 \mathrm{~h}$ work cycle. Iserson studied temperatures inside $\mathrm{CHG}$ and $\mathrm{EHC}$ gloves in extremely low temperatures. The highest initial $\left(36^{\circ} \mathrm{C}\right)$ and final temperatures $\left(28^{\circ} \mathrm{C}\right)$ were found for EHCs. The lowest initial temperature was measured in an EHC with the power turned off $\left(17^{\circ} \mathrm{C}\right)$. Non-heated gloves with an inserted warmer exhibited the lowest minimum temperature $\left(1^{\circ} \mathrm{C}\right)$ [14]. However, the time from heat source activation to deactivation was not accounted for and the study did not reflect the time intervals characteristic of work cycles in cold environments.

Previous research by the present Authors shows that the thermal effects of heating systems used in protective gloves (CHGs or EHCs) should be evaluated under simulated workplace conditions as simple monitoring of inner glove temperature is insufficient to objectively assess thermal effectiveness. Irzmańska et al. reported that cold work environments exhibit some specific characteristics [11]. Under such circumstances, investigations into CHGs and EHCs should involve a series of dynamic tests with measurement intervals reflecting 2 or 3 work cycles lasting approx. $2 \mathrm{~h}$ each as well as 2 or 3 breaks lasting 13-30 min each (Figure 3). Only such methodology can reliably assess the effectiveness of heated systems and evaluate their performance patterns from heat source activation to deactivation (Figure 5). Previous studies on the effects of simulated workplace conditions on commercial warmers with iron powder (without gloves) were conducted by Klarzak et al. [15]. A comparison of commercial chemical warmers was performed based on their thermal effectiveness in ambient and close-to-ambient temperatures. The experiment showed that such warmers remained effective over $6 \mathrm{~h}$. The warmers reached peak temperature when exposed to higher ambient temperatures, which was, however, accompanied by a longer activation time. In another study, Sands et al. [22] found a correlation between the mass of warmers and the intensity and duration of heat production. In the case of iron-based designs, the heavier the warmers, the longer and the more effective their operation. Sands et al. also characterized the work-life thermal behavior of selected commercially-available hand and foot warmers, including peak temperature, time to peak temperature, and duration of temperature greater than $30^{\circ} \mathrm{C}$. Sands et al. noted that while the packaging of most of the studied chemical hand warmers listed an average temperature of $57^{\circ} \mathrm{C}$ with peak temperatures of $65-74^{\circ} \mathrm{C}$ (almost twice as high as for toe and foot warmers), the measured peak temperatures of hand warmers ranged between 44 and $65^{\circ} \mathrm{C}$. The duration of temperature greater than $30^{\circ} \mathrm{C}$ varied significantly both between manufacturers and among warmers of the same type. The shortest heating process lasted for less than 4 hours, while the longest was approx. 9 times longer at 36.5 hours. The limitation of the study by Sands et al. was that all the measurements were made at ambient temperatures, and so the actual performance of warmers against cold was not examined under workplace conditions (i.e., in cold environments). Similar conclusions were also drawn from studies of electrically heated garments (vests) conducted by Wang and Lee [27]. They reported significant differences in heating efficiency at different ambient temperatures due to heat losses to the environment. They concluded that more heat should be delivered by warmers at lower ambient temperatures to ensure satisfactory performance for the desired applications. Thus, 
further research in this area is needed to fully elucidate the problem.

The most popular mineral used in commercially available warmers for maintaining the oxidation reaction by retaining moisture inside the warmers is vermiculite, which is hydrated magnesium-iron-aluminum silicate hydroxide with the chemical formula $(\mathrm{Mg} 2+, \mathrm{Fe} 2+, \mathrm{Fe} 3+) 3 \quad[(\mathrm{SiAl}) 4 \mathrm{O} 10]$ $\mathrm{OH} 2 \cdot 4 \mathrm{H} 2 \mathrm{O}$. Some new solutions use diatomite, which also serves as an insulator for the heat produced. Warmers containing minerals exhibit a heating performance of up to 12 $15 \mathrm{~h}$, maintaining an average temperature of $50-60^{\circ} \mathrm{C}$, which is reached after several minutes of warmer exposure to air. As these types of warmers reach approx. $60^{\circ} \mathrm{C}$, it is critical that they should not get in direct contact with bare skin for fear of causing burns. Elsewhere it has been shown that the most comfortable skin temperature when working in cold environments is $33^{\circ} \mathrm{C}$, with an average between 29 and $33^{\circ} \mathrm{C}$ [16].

The tests showed that the thermal effect was substantially dependent on both the weight of thermoactive compounds in mineral warmers and ambient temperature. Each glove/mineral warmer system exhibited an individual heat release pattern. Glove design and insulating glove materials had little effect on the obtained high temperatures inside protective gloves. Indeed, the application of mineral warmers significantly increased the temperature in the gloves irrespective of the ambient temperature and glove type. In the case of mitts made of polyamide and polyester fibers (palmar region) and polyamide fibers (dorsal region) and five-fingered all-rubber gloves with knitted polyacrylonitrile inserts, the thermal effect was more stable under the adopted experimental conditions. The highest temperature increase was found for five-fingered protective gloves with the palmar region made of wool/polyamide knitwear and polyester knitwear, and the dorsal region made of polyester knitwear and polytetrafluoroethylene membrane.

It should be noted that the present study has certain limitations. The objective of the experiment was to determine the influence of ambient temperature on the effectiveness of mineral warmers placed inside protective gloves, while under actual use conditions the temperature and relative humidity inside protective gloves also depend on the type and duration of work, not to mention individual differences between workers. Thus, further research involving actual workplaces is indispensable to draw comprehensive conclusions.

\section{CONCLUSIONS}

The thermal effectiveness of mineral warmers with different weights (10 g, $20 \mathrm{~g}, 26 \mathrm{~g})$ integrated with protective gloves was studied in a climatic chamber at simulated cold workplace temperatures $\left(10^{\circ} \mathrm{C}, 5^{\circ} \mathrm{C}, 0^{\circ} \mathrm{C},-10^{\circ} \mathrm{C},-15^{\circ} \mathrm{C}\right)$. It was found that:

- Ambient temperature significantly affected the thermal activity of all weight variants of mineral warmers the lower the ambient temperature, the lower the thermal activity of mineral warmers.

- The application of mineral warmers significantly increased the temperature inside all the studied types of protective gloves.

- Mineral warmers with a weight of $10 \mathrm{~g}$ exhibited the lowest thermal activity and a rapid loss of heating ability (after $150 \mathrm{~min}$ of the experiment - at the beginning of the second simulated work interval). Those mineral warmers did not meet the duration requirements, and so may be insufficient to improve the users' thermal comfort in a cold workplace.

Mineral warmers with a weight of $20 \mathrm{~g}$ reached peak temperatures similar to those weighing $26 \mathrm{~g}$, but their thermal activity declined significantly after approx. $180 \mathrm{~min}$ of the experiment (2nd simulated work interval). This warmer variant may be used to improve users' comfort, but for periods shorter than the $6 \mathrm{~h}$ adopted in the study.

Mineral warmers with the highest weight (26 g) exhibited the highest thermal activity ensuring improved thermal comfort for users in cold work environments throughout the adopted $6 \mathrm{~h}$ period.

\section{ACKNOWLEDGMENT}

The publication has been based on the results of Phase IV of the National Programme "Safety and working conditions improvement", funded in the years 2017-2019 in the area of tasks related to services for the State by the Ministry of Family, Labour and Social Policy. The Programme coordinator: Central Institute for Labour Protection - National Research Institute.

The paper is based on the results of COLDPRO project: 'The use of active ecological mineral compounds in the production of cold-protective gloves and footwear' funded in the years $2015-2018$ by National Centre for Research and Development.

\section{REFERENCES}

[1] Fox, W.F. (1967). Human performance in cold. Human Factors, $9(3)$ : 203-220 http://dx.doi.org/10.1177/001872086700900302

[2] Dolez, P.I., Vu-Khanh, T. (2009). Recent developments and needs in materials used for personal protective equipment and their testing. International Journal of Occupational Safety and Ergonomics, 15(4): 347-362. http://dx.doi.org/10.1080/10803548.2009.11076815

[3] Hrynyk, R., Frydrych, I., Irzmańska, E., Stefko, A. (2013). Thermal properties of aluminized and nonaluminized basalt. Textile Research Journal, 83(17): 1860-1872. http://dx.doi.org/10.1177/0040517512447517

[4] Holmer, I. (1993). Work in the cold. Review of methods for assessment of cold exposure. International Archives of Occupational and Environmental Health, 65(3): 14755. http://dx.doi.org/10.1007/bf00381150

[5] Heus, R., Daanen, H.A., Havenith, G. (1995). Physiological criteria for functioning of hands in the cold. Applied Ergonomics, 26(1): 5-13. http://dx.doi.org/10.1016/0003-6870(94)00004-I

[6] Havenith, G., Heus, R., Daanen, H.A. (1995). The hand in the cold performance and risk. Arctic Medical Research, 2: 37-47.

[7] Geng, Q., Chen, F., Holmer, I. (1997). The effect of protective gloves on manual dexterity in the cold environments. International Journal of Occupational Safety and Ergonomics, 3(1-2): 15-29. http://dx.doi.org/10.1080/10803548.1997.11076362

[8] Wang, F. (2014). Modelling of cold stress and cold strain in protective clothing, Protective Clothing. Managing 
Thermal Stress, pp. 366-391. Woodhead Publishing Series in Textiles. http://dx.doi.org/10.1533/9781782420408.3.366

[9] Zimmermann, C., Uedelhoven, W.H., Kurz, B., Glitz, K.J. (2008). Thermal comfort range of a military cold protection glove: database by thermophysiological simulation. European Journal Applied Physiology, 104: 229-236. http://dx.doi.org/10.1007/s00421-007-0660-z

[10] Irzmańska, E., Bacciarelli-Ulacha, A. (2019). Effects of simulated pressure of wooden, plastic, and metal materials on the thermal insulation of cold-protective gloves of various designs. Textile Research Journal, 89(19-20): http://dx.doi.org/10.1177/0040517519829005

[11] Irzmańska, E., Wójcik, P., Adamus-Włodarczyk, A. (2018). Manual work in cold environments and its impact on selection of materials for protective gloves based on workplace observations. Applied Ergonomics, 68: 186196. http://dx.doi.org/10.1016/j.apergo.2017.11.007

[12] Goonetilleke, R.S., Hoffmann, E.R. (2009). Hand-skin temperature and tracking performance. International Journal of Industrial Ergonomics, 39(4): 590-595. http://dx.doi.org/10.1016/j.ergon.2008.01.009

[13] Bellingar, T.A., Slocum, A.C. (1993). Effect of protective gloves on hand movement: an exploratory study. Applied Ergonomics, 24(4): 244-250. http://dx.doi.org/10.1016/0003-6870(93)90458-L

[14] Iserson, K.V. (2016). Glove and mitten protection in extreme cold weather: An Antarctic study. International Journal of Circumpolar Health, 75: 1. http://dx.doi.org/10.3402/ijch.v75.33564

[15] Klarzak, I., Ura-Bińczyk, E., Płocińska, M., JurczykKowalska, M. (2018). Effect of temperature and humidity on heat effect of commercial chemical warmers based on iron powder. Thermal Science and Engineering Progress, 6: 87-94. http://dx.doi.org/10.1016/j.tsep.2018.03.006

[16] Nielsen, R., Nielsen, B. (1984). Measurement of mean skin temperature of clothed persons in cool environments. European Journal of Applied Physiology and Occupational Physiology, 53: 231-236. http://dx.doi.org/10.1007/BF00776595

[17] Makinen, H., Jussila, K. (2014). Cold-protective clothing: types, design and standards, Protective Clothing.
Managing Thermal Stress, pp. 3-38. Woodhead Publishing Series in Textiles.

[18] Xu, P., Wang, F. (2014). Electrically heated clothing (EHC) for protection against cold stress. Protective Clothing. Managing Thermal Stress, pp. 281-295. Woodhead Publishing Series in Textiles. http://dx.doi.org/10.1533/9781782420408.2.281

[19] Wang, F., Gao, C., Kuklane, K., Holmer, I. (2010). A review of technology of personal heating garments. International Journal of Occupational Safety and Ergonomics, 16(3): 387-404.

[20] Oliveira, A.V., Gaspar, A.R., Andre, J.S., Quintela, D.J. (2014). Subjective analysis of cold thermal environments. Applied Ergonomomics, 45: 534-543. http://dx.doi.org/10.1016/j.apergo.2013.07.013

[21] Podella, C.W. (1987). US Patent US4756299A, Chemical heating pad with differing air-admitting perforation sets for different heat-generation levels.

[22] Sands, W.A., Kimmel, W.L., Wurtz, B.R., Stone, M.H., McNeal, J.R. (2009). Comparison of commercially available disposable chemical hand and foot warmers. Wilderness \& Environmental Medicine, 20: 33-38. http://dx.doi.org/10.1580/08-WEME-OR-243.1

[23] Irzmańska, E., Bacciarelli-Ulacha, A. (2020). Case study: Measuring thermal insulation of heated gloves on a thermal hand model. Fibres and Textiles in Eastern Europe, 28(1(139)): 58-64. http://dx.doi.org/10.5604/01.3001.0013.5859

[24] EN 511:2006 Protective Gloves Against Cold. https://guidegloves.com/guidance/standards/en-511/.

[25] Utility model, Application no. W.127804; WIPO ST 10/C PL127804U, Heated glove for occupational and non-occupational applications of 2018.11.21

[26] Song, W., Lai, D., Wang, F. (2015). Evaluating the Cold Protective Performance (CPP) of an Electrically Heated Garment (EHG) and a Chemically Heated Garment (CHG) in cold environments. Fibers and Polymers, 16: 2689-2697. http://dx.doi.org/10.1007/s12221-015-54094

[27] Wang, F., Lee, H. (2010). Evaluation of an electrically heated vest (EHV) using a thermal manikin in cold environments. The Annals of Occupational Hygiene, 54(1):

117-124. http://dx.doi.org/10.1093/annhyg/mep073 